\title{
ANALISIS TINDAK TUTUR PUJIAN DAN RESPON DARI PUJIAN ANTARA ORANG CHINA DENGAN ORANG AMERIKA DALAM FILM "CRAZY RICH ASIANS"
}

\section{Muhammad Rizal Alfarisi}

Ilmu Linguistik Fakultas Ilmu Budaya Universitas Airlangga, Surabaya, Indonesia

Email: rizal.alfarisi@gmail.com

\begin{abstract}
Abstrak
Penelitian ini meneliti tentang penggunaan ujaran pujian pada film Crazy Rich Asians, dalam film ini terdapat dua kebudayaan yang berbeda dan salling berkomunikasi satu sama lain, diantaranya orang China dan orang Amerika. Penelitian ini meneliti tentang penggunaan pujian dan responnya yang terdapat pada film tersebut. Peneliti menemukan 50 data pujian dan 35 data respon dari pujian didalam film. Orang China sering menggunakan pujian penampilan pada lawan bicaranya, sedangkan orang Amerika banyak menggunakan pujian kepribadian. Dan respon pujian dari keduanya menunjukkan sedikit perbedaan, orang amerika sering menggunakan appreciation token dalam merespon pujian dan tidak tersenyum, sedangkan orang Chinese sering menggunakan return respond untuk merespon sebuah pujian dari orang lain.
\end{abstract}

Kata Kunci: pujian; respon pujian; film

\begin{abstract}
This research is investigates about the compliment that used in fim Crazy Rich Asians, in this Film there two culture that communicate each other, between Chinese people and American people. This study tries to investigate the using of compliment in this film and the respond of the compliment. The researcher found 50 data about the compliment and 35 data about the respond of the compliment. The Chinese people often used appearance compliment to the others, then the American people often used personality compliment, and the respond of the compliment itself looks little different between the American people and the Chinese people, The American People often used the appreciation token to respond the compliment and not smile when the other giving compliment to them and the Chinese people used return to respond the compliment that uttered by others.
\end{abstract}

Keywords: compliment; compliment respond; film

Received: 2021-10-20; Accepted: 2021-11-05; Published: 2021-11-20

$\begin{array}{ll}\text { How to cite: } & \text { Alfarisi. M. R (2021) Analisis Tindak Tutur Pujian dan Respon dari Pujian antara Orang China Dengan } \\ & \text { Orang Amerika dalam Film “Crazy Rich Asians”, } 6 \text { (2), Syntax Literate: Jurnal Ilmiah Indonesia } \\ \text { E-ISSN: } & \text { 2548-1398 } \\ \text { Published by: } & \text { Ridwan Institute }\end{array}$




\section{Pendahuluan}

Bahasa merupakan sebuah alat untuk berkomunikasi, interaksi, dan mengungkapkan emosi dan perasaan yang digunakan untuk manusia, di lingkungan kita tinggal, bahasa juga berfungsi untuk bertukar informasi antara satu dengan yang lain. Bahasa merupakan sebuah alat untuk mengungkapkan sebuah maksud, arti, dan pesan yang bisa berpindah dari satu bahasa ke bahasa yang lain (Wierzbicka, 2003). Di dunia ini terdapat banyak bahasa yang digunakan oleh penduduk bumi dan memiliki ratusan ribu variasi. Persebaran bahasa sendiri juga bergantung dari nilai budaya masyarakat sekitar, yang bisa melahirkan banyak bahasa di berbagai negara. Sementara itu, perbedaan dari budaya bisa juga mengakibatkan lahirnya bahasa yang berbeda dilingkungan sekitar. Latar belakang budaya sangat membentuk cara orang bereaksi dan berinteraksi satu sama lain, beberapa budaya menjunjung tinggi nilai budayanya dan tercermin ke dalam penggunaan bahasa dan cara berkomunikasi yang dilakukan oleh seseorang atau kelompok yang menganut budaya tertentu (Alsohaibani, 2017). Akibat dari perbedaan budaya ini bisa menyebabkan kesalahpahaman tentang makna yang berusaha disampaikan oleh penutur sendiri didalam suatu lingkungan berbahasa.

Dalam menyampaikan tuturan seseorang harus memperhatikan juga kepada siapa penutur berbicara, Austin (1962) yang pertama kali mengemukakan teori tindak tutur dan mengkategorikannya menjadi tiga kategori, yaitu lokusi (melakukan tindakan untuk mengatakan sesuatu), ilokusi (melakukan tindakan dengan mengatakan sesuatu), dan perlokusi (hasil dari suatu tindak dengan mengatakan sesuatu). Dalam teori yang dikemukakan oleh Austin (1962) Ilokusi diklasifikasikan menjadi lima subjenis lagi, yaitu verdiktif, eksersitif, komisif, behavitif, dan ekspositif. Terdapat lima sub-bagian dari ilokusi yang diantaranya asertif, direktif, ekspresif, komisif, dan deklarasi (Searle \& Searle, 1969).

Berdasarkan uraian diatas, penulis menggunakan pendekatan pragmatik lintas budaya, pragmatik sendiri merupakan bidang kajian ilmu yang mempelajari tentang "makna dari sebuah perkataan" yang dikatakan oleh penutur, yang dimana apabila kita memiliki sebuah perbedaan dari tata bahasa ataupun dari budaya dapat menimbulkan kesalahpahaman dalam memaknai sesuatu yang diucapkan oleh penutur sendiri. Orang Jepang cenderung mengatakan suatu perkataan secara tersirat (indirect) sedangkan orang amerika sering berkata dengan langsung menuju pada inti pembicaraan (direct), ketepatan (directness) harus disampaikan dalam kebudayaannya masing- masing agar tidak timbul salah persepsi dalam menangkap sebuah pesan yang disampaikan (Wierzbicka, 2003). Dalam kehidupan bersosial seorang manusia pasti berusaha memahami perkataan penutur untuk memperoleh pesan yang disampaikan, melalui pragmatik lintas budaya ini seorang manusia bisa mengerti dan memahami tentang budaya dan Bahasa yang terkandung didalamnya.

Bahasa sendiri tercermin dalam budaya yang menyebabkan perbedaan didalamnya, meski dalam negara yang sama. karena dalam satu negara sendiri bisa memiliki variasi Bahasa yang cukup banyak. Dalam beberapa dekade, keberadaan tentang pragmatik lintas budaya yang mempengaruhi banyak peneliti untuk meneliti 
tentang kebudayaan dan bahasa. studi lintas bahasa dan budaya akan memudahkan pembelajaran bahasa lintas batas dan mengatasi penyebab apa pun yang mungkin menyebabkan gangguan komunikasi di antara penutur dari latar belakang tata bahasa yang berbeda (Meier, 2010, Al-Mansoob, Patil, \& Alrefaee, 2019, Alrefaee, Mudkanna, Almansoob, \& Alrefaee, 2019). Tindak tutur membedakan budaya yang berbeda bukan hanya dari cara mereka merealisasikannya tetapi juga dari hal pendistribusiannya, frekuensi kemunculannya, dan dalam fungsi yang mereka peroleh. kekuatan ilokusi dari tindak tutur yang diucapkan sangat ditentukan oleh norma kesantunan budaya masyarakat tutur (Wolfson, 1981). Penutur asli bahasa Arab sangat berbeda dengan penutur asli bahasa Inggris dalam cara bicaranya sebagai realisasinya karena budaya Arab sangat mengatur tingkat kesopanannya dalam berbicara dengan sesamanya ataupun orang lain (Ghazzoul, 2019).

Ada beberapa penelitian sebelumnya yang menganalisa tentang tindak tutur, diantaranya adalah Dina (2019) yang menganalisa tentang tindak tutur ekspresif yang digunakan dalam acara Galau Nite di Metro TV dengan hasil bahwa tindak tutur ekspresif yang di analisa telah ditemukan tindak tutur mengucapkan selamat (30\%), terima kasih (30\%), mengkritik (5\%), mengeluh (5\%), menyalahkan, memuji (10\%), meminta maaf (10\%), serta menyindir (10\%). Dari hasil penelitian tersebut bisa disimpulkan bahwa dalam acara TV tersebut baik narasumber ataupun pembawa acara pada acara TV tersebut lebih banyak mengucapkan terima kasih dan selamat karena apresiasi yang sudah diraih oleh narasumber yang menjadi bintang tamu dalam acara tersebut.

Selanjutnya dari Keshavarz, Çetereisi, dan Asit (2020) yang menganalisa tentang penggunaan tindak tutur pujian pada TV drama Turki, dari hasil penelitian mereka, mereka menemukan bahwa pengguaan tindak tutur pujian selalu digunakan oleh lakilaki yang berusaha mendapatkan hati seorang perempuan dan temannya, didalam tindak tutur pujian tersebut pujian sering digunakan untuk memuji penampilan dari lawan bicaranya, fungsinya untuk membuat seseorang merasa disegani dan diakui oleh orang lain, oleh karena itu mereka sering menggunakan pujian.

Kemudian, penelitian sebelumnya tentang respon dari pujian, diantaranya Farinda (2016) yang menganalisa tentang respon dari pujian dalam film "You”, hasil dari analisanya menemukan bahwa responnya sendiri digolongkan kedalam dua bagian yaitu verbal dan non-verbal. Ditemukan pada data yang memberikan respon pujian dengan bahasa nonverbal, seperti memberikan senyuman dan menganggukkan kepala, respon non-verbal tersebutlah yang paling banyak digunakan oleh karakter dalam film "You", kemudian pada respon verbal sendiri karakter dalam film tersebut sering menggunakan kata seperti "Thank you".

Terdapat peneliti lain yang meneliti topik sama, yaitu tentang respon dari pujian, Xia, Yin, dan Lan (2021) menemukan bahwa sebuah pasangan china (suami-istri) cenderung mmeberikan respon dari sebuah pujian dengan menerimanya, berbeda apabila kedekatan antara tiga orang (suami-istri-adik) yang cenderung menolak suatu pujian karena faktor kedekatan sebelumnya. Disini terdapat pengaruh dari barat tentang 
repson suatu pujian yang justru akan menolak suatu pujian apabila dipuji oleh lawan bicaranya.

Disamping itu terdapat penelitian sebelumnya yang membahasa tentang pujian dan responnya yang digunakan oleh mahasiswa universitas yahudi yang berada Israel yang dilakukan oleh Danziger (2018), dalam penelitiannya dia menemukan bahwa sebuah pujian dibagi kedalam dua bagian yaitu pujian internal (penampilan fisik, bakat, dan kepribadian) dan pujian eksternal (penampilan, kepemilikan, dan prestasi), mahasiswa yang berada di Israel khususnya mahasiswa di universitas yahudi kebanyakan merespon sebuah pujian dengan senyum dan mengucapkan terima kasih kepada si pemuji.

Berdasarkan beberapa studi sebelumnya yang sudah disebutkan diatas, dari Dina (2019) dan Keshavarz et al. (2020) yang berfokus pada objek sebuah acara di suatu kanal televisi, mereka menganalisa hanya pada bentuk pujian-pujian yang digunakan dalam sebuah acara kanal televisi tersebut dan tidak menyertakan respon dari orang yang telah dipuji. Selanjutnya dari Farinda (2016) yang melakukan penelitian menggunakan objek mahasiswa asing dan mahasiswa Indonesia sebagai penelitiannya, Disini peneliti mencoba mengisi celah dari penelitian-penelitian sebelumnya yaitu dengan meneliti macam dari pujian yang digunakan dan respon dari seseorang yang dipuji dalam sebuah film Crazy Rich Asians, didalam film tersebut terdapat dua kebudayaan yang berbeda dan diharapkan bisa mengisi celah diantara studi-studi sebelumnya.

Film Crazy Rich Asians sendiri merupakan film yang menceritakan hubungan percintaan antara orang amerika yang menikah dengan orang china dan dikaruniai anak yang sangat cerdas dia bernama Rachel, dia bisa bicara Bahasa inggris dengan sangat baik tapi tidak dengan Bahasa china, karena dia sudah puluhan tahun tinggal Bersama kedua orang tuanya di Amerika. Kemudian dia bertemu dengan anak salah satu konglomerat dari china yang bernama Nick Young dan mereka-pun berpacaran, mereka saling mencintai satu sama lain dan mereka menemukan halangan terbesar dalam hubungannya yaitu mendapatkan restu dari ibu Nick Young yang membanci Rachel karena latar belakang kehidupannya.

Tujuan dalam penelitian adalah peneliti menganalisa tentang macam dari sebuah pujian dan cara mereka merespon suatu pujian yang digunakan oleh dua kebudayaan yang berbeda yaitu orang China dan orang Amerika. Dalam penelitian ini peneliti menggunakan tabel perbandingan agar mudah dibaca. Terakhir, peneliti berharap temuan dalam penelitian ini dapat menjadi referensi yang baik bagi pembelajar linguistik dan dapat dieksplorasi lebih lanjut oleh peneliti selanjutnya.

\section{Metode Penelitian}

Metode deskriptif kualitatif, yang dapat diartikan sebagai prosedur pemecahan masalah yang diselidiki dengan menggambarkan/melukiskan keadaan subjek/objek penelitian (seseorang, lembaga, masyarakat dan lain-lain) pada saat sekarang berdasarkan fakta-fakta yang tampak atau sebagaimana adanya (Soedjono, 1999). Untuk 
sumber data sendiri penulis mengambil data tuturan dari semua pemain dalam film Crazy Rich Asians yang mengandung unsur pujian, filmnya di unduh melalui https://185.231.223.71/ dan untuk teks terjemahan dalam Bahasa Indonesia di unduh pada halaman https://subdl.com/s/subtitle/sd17927/crazy-rich-asians.

Peneliti menggunakan Film Crazy Rich Asians sendiri karena didalamnya terdapat dua kebudayaan dengan latar belakang yang berbeda saling berinteraksi satu sama lain dan memiliki cerita yang menarik, dalam menganalisa data peneliti mempunyai dua tahap, yaitu (1) tahap pengamatan dan pencatatan; (2) tahap Analisa. Dalam tahap pertama peneliti memperhatikan tuturan yang mengandung pujian dan bagaimana respon seseorang jika dipuji didalam film. Lalu pada tahap kedua peneliti mengelompokkan tuturan menurut teori Holmes dan respon terhadap pujian menurut teori dari Herbert.

\section{Pembahasan}

\section{Macam Pujian}

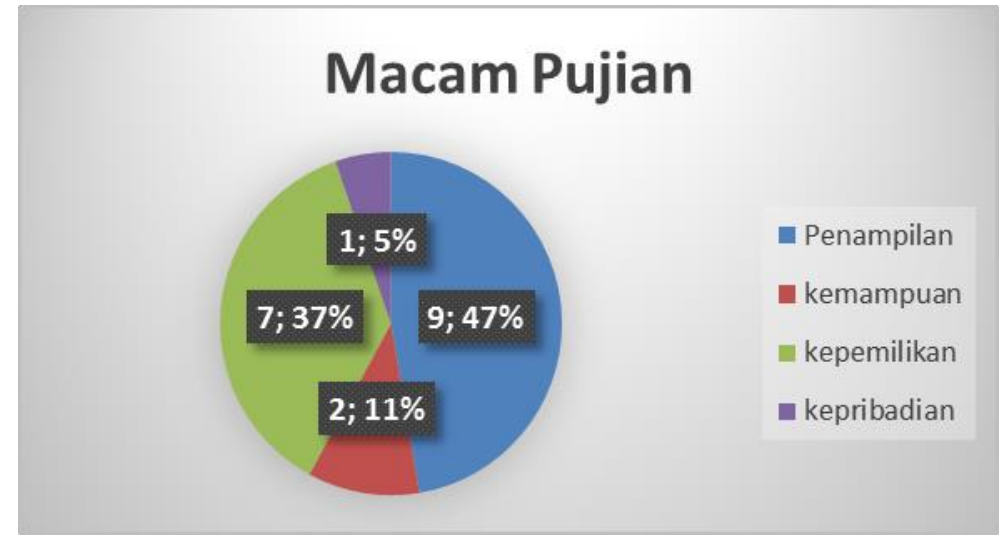

Gambar 1

Penggunaan Pujian dari orang China dalam Film Crazy Rich Asian

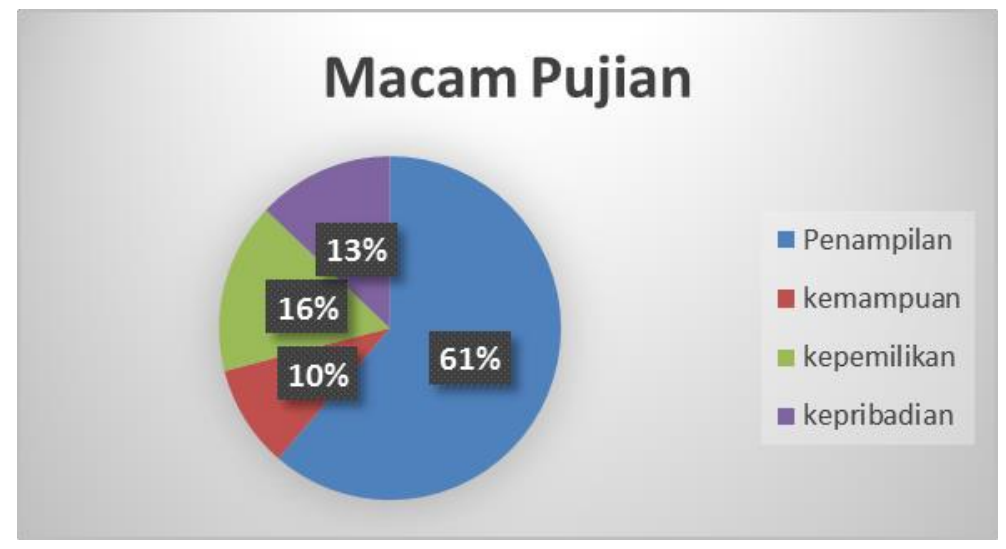

\section{Gambar 2}

Penggunaan pujian dari orang Amerika dalam film Crazy Rich Asian 
Untuk menjawab rumusan masalah nomor 1 penulis mengkategorikan beberapa pujian yang ditemukan kedalam empat kategori beradasarkan teori yang dikemukakan oleh Holmes (1986). Berikut uraiannya.

\section{1) Penggunaan Pujian dari Orang china}

Data 1

Nick : Kita sudah pacaran lebih dari setahun... Kurasa sudah saatnya mereka Bertemu pacarku yang Cantik ini. Ayolah, aku sahabat baik Colin.

Nick ingin mengenalkan pacarnya kepada ibunya. Dengan memujinya "cantik" untuk bisa meyakinkan Rachel pergi ke china untuk dipertemukan dengan ibunya. Pujian ini termasuk pujian tentang penampilan, berdasarkan teori dari Holmes (1986) karena pada tuturan tersebut Nick memujinya agar Rachel mau pulang bersamanya ke china. Disini Nick memuji Rachel dengan berkata secara langsung karena dengan ini Nick yakin bahwa Rachel pasti mau untuk diajak ke pulang ke kampung halamannya Nick untuk bertemu dengan ibunya.

Data 2

$$
\begin{array}{ll}
\text { Astrid } & \text { :Apa itu? } \\
\text { Liong } & \text { : Itu? Itu sangat istimewa. Anting - anting mutiara Burma, } \\
& \text { berhiaskan zamrud dan rubi merah darah merpati langka. Itu } \\
& \text { dipakai oleh Ratu Zubriella Saat penobatan dirinya tahun } 1878 . \\
\text { Astrid } \quad: \text { Berapa harganya? } & \text { Liong } \quad \text { Kau memakai salah satu barangku merupakan publikasi yang tak } \\
& \text { bisa kubeli. Kujual dengan harga murah, \$1,2 juta. }
\end{array}
$$

Liong adalah penjualan emas dan perhiasan yang sangat terkenal dengan desainnya di daratan china, sedangkan Astrid merupakan sepupu Nick yang merupakan bagian dari keluarga terkemuka di china. Pada kalimat yang ditandai dengan menebalkan tulisan tersebut merupakan sebuah bentuk pujian yang berfungsi untuk membuat Astrid membeli perhiasan yang dia jual. berdasarkan teori yang dikemukakan holmes kalimat tersebut masuk dalam kategori pujian ciri-ciri Kepribadian yang digunakan secara tak langsung, Karena barang apapun yang dipakai salah seorang konglomerat akan jadi terkenal dan banyak peminat karena mereka termasuk orang berpengaruh dalam lingkungannya.

Data 3

Nick : Aku jatuh di lantai dan dia duduk di atasku, jadi Itu bukan perkelahian.

Niko : Mari bersulang untuk sahabat baik-ku, Nick Young Yang tak bisa bertarung gila - gilaan. Tapi dia selalu membantumu.

Nick bertemu teman kecilnya yang Bernama Niko yang kebetulan akan merencanakan pernikahan dengan pesta terbesar Bersama calon istrinya Araminta. Dia 
menceritakan sedikit masa lalunya pada Araminta dan Rachel. Pada kalimat yang diberi tanda tebal diatas, merupakan kalimat pernyataan yang menyatakan pujian pada Nick atas perbuatannya di masa lalu yang selalu menghajar temannya karena selalu membuat Niko menangis, menurut teori dari Holmes (1986) kalimat tersebut masuk ke dalam kategori Pujian terhadap kemampuan Nick dalam menghadapi musuh dari temannya yang biasanya membuat sahabatnya menangis.

Data 4

\section{Astrid : Untuk merayakan peluncuran startup-mu, aku tahu kau tak suka hadiah mahal, tapi kau bukan Kapten pasukan lagi kau CEO, kau harus terbiasa.}

Astrid memberikan selamat kepada Michael yang merupakan suaminya karena dia baru saja berhasil membangun sebuah usaha startup dan Astrid memberikan penghargaan berupa hadiah berupa jam tangan kepadanya. Dari teks yang ditebalkan tersebut terlihat bahwa Astrid memberikan sebuah hadiah yang tidak murah kepada suaminya atas berdirinya perusahaan baru milik suaminya,. Apa yang dilakukan Astrid termasuk pujian tentang Kemampuan, karena dari situlah kita bisa melihat bahwa Michael berhasil menjadi CEO dari perusahaan yang baru saja di bangun dan Astrid mengapresiasi jerih payah suaminya tersebut dengan memberikannya sebuah kado.

Data 5

Tuan Goh : Kami sangat Bersyukur atas segala bantuan yang kau berikan pada Peik Lin Saat dia kuliah. tanpa bantuanmu, dia pasti sangat kacau.

Rachel : Ya Tuhanku, tidak, sebenarnya, jika bukan karena dia, aku yang kacau, dia sangat membantuku saat kuliah. senang bertemu denganmu, Tn. Goh.

Tuan Goh sangat senang atas kedatangan Rachel kerumahnya dan juga berterima kasih kepada Rachel atas bantuan yang diberikan Rachel kepada Peik Lin semasa kuliah. Dari kalimat yang ditebali diatas menunujukkan bahwa ayah dari Peik Lin sangat berterima kasih atas bantuan Rachel yang Dari kalimat diatas juga kita bisa mengkategorikan kalimat tersebut kedalam kategori pujian terhadap Kemampuan, karena Rachel bisa membantu sahabatnya lulus dengan tepat waktu Peik Lin kuliah di New York.

Data 6

Nick : Hai, cantik. kurasa aku jatuh cinta padamu lagi Rachel!

Rachel : Aku juga merindukanmu. Oh, dia temanku, Peik Lin.

Nick $\quad$ : Hei, Pek Lin apa kabar? Terima kasih banyak sudah mengantarkan Rachel.

Rachel dan Peik Lin menghadiri acara yang diadakan keluarga Nick dan merekapun disambut oleh Nick, Dari kalimat yang diberi tanda diatas menandakan bahwa Nick memuji Rachel karena dia terlihat sangat cantik di acara yang diadakan 
dirumah Nick, dia sangat senang melihat Rachel saat itu. Pujian yang diberikan Nick kepada Rachel masuk kedalam kategori pujian tentang Penampilan, karena dia mengatakan bahwa dia bahkan jatuh cinta lagi kepada Rachel dia menggunakan gaun yang membuatnya sangat cantik.

Data 7

\author{
Oliver : Antingmu cantik \\ Rachel : ini mudah dilepas. \\ Oliver : Sungguh? \\ Rachel : Jadi, Oliver, kau juga sepupunya? \\ Oliver : Yah, aku salah satu orang asia miskin orang nyeleneh di keluarga \\ ini. Tapi kubuat diriku berguna, apapun yang Keluarga Young \\ inginkan, aku menyediakannya.
}

Rachel bertemu dengan salah satu keluarga Nick yang juga termasuk sepupu Nick, Namanya Oliver. Dia seorang pengusaha yang menyediakan kebutuhan keluarga Nick. Dari kalimat yang ditandai diatas Rachel memuji Oliver karena antingnya terlihat sangat bagus, Ucapan Oliver yang memuji anting Rachel masuk kedalam kategori pujian tentang Kepemilikan, Rachel memuji anting yang dipakai oleh Oliver dan dia sebenarnya menginginkan anting itu tapi dia tidak bisa memilikinya.

Data 8

Rachel : Hanya perasaanku atau semua orang melihatiku?
Oliver : mereka cemburu. kau merebut pangeran mahkota. Nicky itu kesukaan Ah Ma. Dia termasuk yang akan mewarisi segalanya. Tak mengejutkan kalau ada kompetisi. Oh, itu dia wanita pemilik kebun.

Rachel yang tiba ke acara jamuan makan yang diadakan oleh nenek Nick merasa bahwa dia diperhatikan banyak orang disekitarnya. Pujian yang dilakukan oliver memiliki fungsi, yaitu untuk membuat Rachel menjadi lebih kuat dan tidak memperhatikan lingukungan di sekitarnya, oleh karena itu Oliver juga menjelaskan bahwa Rachel-lah wanita yang beruntung yang dipilih oleh Nick sebagai calon istrinya.sebuaha pujian yang dilakukan oleh Oliver masuk kedalam kategori pujian tentang Penampilan, karena para tamu yang berada di jamuan makan saat itu memandangi penampilan Rachel yang bahkan tidak pantas untuk menjadi calon istri Nick.

Data 9

Ah ma : Kau sudah makan? Kau jadi kurus

Nick : Itu karena aku rindu masakanmu, oh ya ini teman baik-ku, Rachel

Setelah sekian lama Ah ma tidak melihat Nick, akhirnya mereka bertemu dan saling berbincang satu sama lain. Pada kesempatan ini Nick mencoba mengenalkan 
wanita yang ia cintai kepada Ah ma, dia Rachel. Pada kesempatan ini Rachel diberi waktu untuk berjumpa Ah ma Nick dan mereka berbincang.

Dari kalimat diatas yang ditandai, menandakan bahwa Nick mencoba memuji masakan neneknya yang begitu lezat hingga beberapa lama tak bertemu dengannya dan dia menjadi kurus namun itu hanya alasan semata yang digunakan Nick untuk memuji neneknya yang sudah lama tidak berjumpa. Kalimat diatas masuk kedalam kategori pujian terhadap kemampuan nenenk Nick yang bisa membuat masakan paling enak.

\section{2) Penggunaan Pujian dari orang Amerika}

Data 10

Rachel: Kau tahu? Kau bisa memesan sendiri.

Nick : Aku pesan kopi saja, terima kasih.

Rachel: Ya, kau selalu mengatakan itu..,.. Lalu kau menghabiskan semua pencuci mulutku

Rachel merupakan anak dari warga amerika yang menikah dengan keturunan china dan dia sudah menetap di Amerika selama puluhan tahun, sebenernya Rachel sudah memuji Nick tapi Nick tidak menggubrisnya karena dia merasa dia tidak mempunyai apapun, Fungsi tindak tutur pujian yang diucapkan oleh Rachel adalah agar Nick mempunyai dorongan memesan kue sendiri tapi itu tidak berpengaruh kepadanya, pujian yang digunakan oleh Rachel masuk kedalam kategori Kepemilikan. Karena seperti penjelasan dari Holmes mengenai tuturan Rachel yang berusaha memuji jika Nick memiliki segalanya dan Rachel tahu bahwa sebenarnya Nick mempunyai uang lebih untuk membeli sebuah kue yang dia inginkan.

Data 11

Rachel : Jadi, keluargamu itu..,.Kaya?

Nick : Kami sederhana.

Rachel : Itu yang selalu dikatakan orang super kaya. Jujur itu bukan masalah besar, aku Hanya... Rasanya aneh aku tak tahu sama sekali tentang keluargamu

Karena Nick tak pernah menceritakan apapun tentang keluarganya yang menjadi salah satu konglomerat di china, Rachel mulai berspekulasi bahwa dia istimewa atau berasal dari keluarga istimewa di rumahnya, Bentuk pujian yang dikatakan oleh Rachel merupakan pujian dalam bentuk menyindir, Rachel berkata demikian supaya Nick mengaku bahwa keluarganya merupakan orang terkaya di china tapi tetap saja dia tidak mau mengakuinya. Dari pujian diatas termasuk kedalam kategori ciri-ciri kepribadian karena meski Nick dipuji oleh Rachel tapi dia tetap rendah hati pada Rachel yang menjad lawan bicaranya saat itu.

Data 12
Bibi Goh
: Rachel! Selamat datang!
Rachel
:Wauw ! Astaga! Rumahmu luar biasa sekali, Ny. Goh.
Bibi Gooh
: Ucapanmu manis sekali. 
Rachel baru saja datang kerumah Peik Lin, Rachel memberikan pujian kepada Bibi Goh karena Rachel sangat suka melihat rumah Bibi Goh yang terlalu besar untuk tempat tinggal Rachel sementara saat berada di china, Kalimat yang ditandai diatas merupakan kategori Pujian terhadap kepemilikan, karena didalamnya terdapat kalimat bahwa Rachel sendiri tidak dapat memiliki rumah tersebut meski 30 tahun dia kerja dan Rachel sangat menghargai keputusan Peik Lin untuk mengizinkan Rachel tinggal dirumahnya sementara waktu selama dia berada di china untuk menghadiri acara pernikahan Niko yang akan diadakan seminggu kedepan.

Data 13

\section{Rachel : Tempat ini mengagumkan dengan lembah hijaunya ada pasukan bersenjata di luar sana dan harimau raksasa.}

Nick $\quad$ : Baik. Itu tuan Harima kakek buyutku menembaknya saat harimau itu lari menuju rumah.

Nick mengajak Rachel masuk kedalam rumahnya yang penuh dengan tamu dan menunjukkannya ruangan koleksi kakek buyutnya yang kemudian dia menceritakan tentang dirinya juga semasa kecil yang pada saat itu tinggal dirumah neneknya. Dari kalimat yang ditandai diatas dijelaskan bahwa Rachel memuji Nick atas rumah neneknya yang begitu megah dan mewah. Pujian Rachel yang digunakan saat ini masuk kedalam kategori pujian Tentang kepemilikan, karena Rachel merasa bahwa rumah nenek Nick besar sekali dan akan dia akan menjadi istri dari Nick oleh karena itu Rachel sangat terkagum dengan apa yang Nick miliki di China.

Data 14

\section{Rachel : Ah Ma, Terima kasih sudah mengundangku ke rumahmu, rumahmu sangat indah.}

Nick : Dia Ling Cheh.Mantan pengasuhku.

Rachel yang baru saja bertemu dengan saudara-saudaranya Nick Ketika berkunjung kerumahnya di China, Dalam kalimat yang sudah ditandai diatas dia berterima kasih kepada nenek Nick yang sudah mengundangnya untuk mengikuti acara jamuan makan malam Bersama aggota keluarga besar Nick, dia sangat senang karena telah diundang ke jamuan makan malam tersebut. Kalimat pujian diatas masuk kedalam kategori Kepemilikan, karena Rachel memuji nenek Nick karena memiliki rumah yang begitu megahnya.

\section{Respond of Compliment}

Selanjutnya merupakan jawaban dari rumusan masalah nomor 2, yang dianalisis menggunakan teori dari Herbert (1989) berikut uraian dan pembahasan dari rumusan masalah nomor 2:

\section{1) Respon pujian orang Amerika}

Data 1

Nick : Kau begitu Sempurna malam ini, aku jatuh cinta padamu lagi

Rachel : Terima kasih Nick, aku mencintaimu 
Nick yang memuji Rachel karena penampilannya yang begitu indah menurutnya, dilain sisi Rachel memperlihatkan respon dari pujian Nick, respon dari Rachel sendiri masuk kedalam kategor respon pujian Appreciation Token.

Data 2

Astrid : Sepertinya kau berhasil mengalihkan perhatian pangeran mahkota

Rachel : Tidak, aku tak secerdik dirimu yang bisa membuat emas menghilang hanya dalam kedipan mata

Astrid memuji Rachel karena kepiawaiannya dalam mendapatkan hati seorang pangeran mahkota yaitu Nick, Namun respon Rache pada pujian seolah-olah dia tidak ada bandingannya dibandingkan dengan Astrid sendiri yang bisa seolah-olah membuat mata semua orang tertuju padanya. Pada bagian data ini respon dari Rachel termasuk kedalam respon pujian Scale Down.

Data 3

Peik Lin : Hei! Kau memang bisa diandalkan daridulu

Rachel : Terima kasih atas pujiannya

Peik Lin memberikan suatu pujian kepada Rachel karena kepiawaiannya dalam memecahkan soal ekonomi, pujian tersebut kemudia direspon oleh Rachell dengan kata "terima kasih", kategori pujian yang dilakukan oleh Rache masuk kedalam kategori “Appreciation Token”.

Data 4

Eleanor : Kau orang yang paling berani yang pernah kutemui

Rachel : Maaf, aku tidak seberani itu sampai harus membuat anakmu tidak patuh terhadap perkataanmu

Eleanor memuji Rachel yang sudah berhasil membuat Nick Jatuh cinta padanya, namun respon Rachel sangatlah membuat si penutur pujian merasa jengkel, respon dari Rachel masuk kedalam respon kategori "Scale Down".

Data 5

Nick : Karena kau telah menumbuhkan bunga dihatiku, Rachel yang menawanku

Rachel : iya, ada apa Nick?

Nick yang memuji muji Rachel Nampak taka ada tanggapan, justru dia malah menanyakan balik, Disini Rachel tidak merasa bahwa dirinya sedang dipuji oleh karena itu responnya menunjukkan seperti dia kebingungan, respon dari Rachel masuk kedalam kategori "Non-Acknowledgement".

1) Respon pujian orang China

Data 6

Rachel : mengapa engkau yang rupawan begini bisa jatuh cinta padauk?

Nick : entah, mungkin karena aku memang tertarik padamu dan aku bisa menjadi diriku sendiri apabila bersamamu dan aku tahu aku bisa hidup bahagia bersamamu

Rachel yan mencoba memuji Nick justru mendapatkan respon yang sangat mengejutkan, karen terlihat seperti Nick yang balik memujinya saat mereka berdua 
berbicara. Respon yang dilakukan Nick terhadap pujian Rachel merupakan respon pujian "Return”.

Data 7

Oliver : Nick kau memang anak yang paling bisa diandalkan di keluarga ini

Nick : Ini memang sudah kewajibanku menuruti apa yang ibu katakana

Sebuah pujian dari oliver tentang diri Nick merupakan pujian yang disampaikan secara tersirat, dan Nick pun meresponnya dengan secar tersirat juga. Respon dari Nick sendiri merupakan respon kategori "Qualification”

Data 8

\section{Eleanor : kepandaianmu dalam merencanakan suatu rencana memang patut dibanggakan, kau telah berhasil menjadikan acara ini menjadi banyak pengunjung}

Oliver : tidak nyonya, ini memang sudah kewajibanku melayani anda dan yang keluarga anda butuhkan

Eleanor tampak memuji Oliver yang berhasil mengatur sebuah acara sesuai dengan keinginan Eleanor, namun respon dari oliver memperlihatkan bahwa apa yang dilakukannya itu memang sebuah kewajiban yang wajib dia jalankan sebagai pelayan keluarganya, respon dari Oliver termasuk respon yang masuk kedalam kategori "praise upgrade".

\section{Kesimpulan}

Dari semua yang sudah ditulis diatas, disini penulis menggunakan teori yang dikemukakan Holmes untuk mencari kategori dari pujian-pujian yang dibicarakan oleh beberapa karakter pada film Crazy Rich Asians, dalam film ini terdapat interaksi antara orang amerika dengan orang china dengan sumber satu orang amerika-china yang tidak bisa berbahasa china.

Dari data yang sudah dianalisis terdapat kurang lebih 4 kategori pujian yang ditenukan dalam film ini menggunakan teori yang dikemukakan oleh Holmes, yaitu pujian terhdap kepemilikan, pujian terhadap pujian terhadap penampilan, dan pujian terhadap kepribadian. Dari hasil yang didapatkan selama penelitian orang China selalu melakukan pujian dengan tersirat dan orang Amerika sering melakukan pujian secara langsung. Namun terdapat perbedaan yang tipis diantara keduanya karena mereka samasama menempuh Pendidikan yang sama selama di Amerika.

Kemudian dalam hal merespon dari pujian, terdapat 6 kategori yang ditemukan dalam Analisa film Crazy Rich Surabaya, yaitu: Appreciation Token, Return, Praise Upgrade, Non-Acknowledgement, Scale down, dan Qualification. Diantara keenam kategori tersebut orang Amerika lebih banyak menggunakan Appreciation Token dan Praise Upgrade, dan Orang China lebih banyak Return dalam merespon suatu pujian. Dari sini peneliti sudah menjawa semua rumusan masalah diatas 
Analisis Tindak Tutur Pujian dan Respon dari Pujian antara Orang China Dengan Orang Amerika dalam Film "Crazy Rich Asians"

\section{BIBLIOGRAPHY}

Al-Mansoob, Najeeb Taher, Patil, K. S., \& Alrefaee, Yasser. (2019). A Cross-cultural study of the speech act of compliments in American English and Yemeni Arabic. LANGKAWI Journal, 5(1), 1-12. Google Scholar

Alrefaee, Sara, Mudkanna, Anita, Almansoob, Najeeb, \& Alrefaee, Yasser. (2019). The Effect of Yemeni EFL Learners' Low Listening Proficiency on Their Performance in the TOEFL IBT Integrated Test of Writing. Language in India, 19, 3. Google Scholar

Alsohaibani, Ali. (2017). Influence of Religion on Language Use: a sociopragmatic study on the influence of religion on speech acts performance. University of East Anglia. Google Scholar

Austin, J. L. (1962). Speech acts. Oxford. Google Scholar

Danziger, Roni. (2018). Compliments and compliment responses in Israeli Hebrew: Hebrew university in Jerusalem students in interaction. Journal of Pragmatics, 124, 73-87. Google Scholar

Ghazzoul, Nahed. (2019). Linguistic and pragmatic failure of Arab learners in direct polite requests and invitations: A cross-cultural study. Theory and Practice in Language Studies, 9(2), 223-230. Google Scholar

Herbert, Robert K. (1989). The ethnography of English compliments and compliment responses: A contrastive sketch. Contrastive Pragmatics, 3-35. Google Scholar

Holmes, Janet. (1986). Compliments and compliment responses in New Zealand English. Anthropological Linguistics, 485-508. Google Scholar

Keshavarz, Mohammad Hossein, Çetereisi, Yasemin, \& Asit, Gulay. (2020). Pragmatic Features of the Speech Act of Compliment in a Turkish TV Drama. Journal of Pragmatics Research, 2(1), 1-25. Google Scholar

Searle, John R., \& Searle, John Rogers. (1969). Speech acts: An essay in the philosophy of language (Vol. 626). Cambridge university press. Google Scholar

Wierzbicka, Anna. (2003). Singapore English: A semantic and cultural perspective. Google Scholar

Wolfson, Nessa. (1981). Compliments in cross-cultural perspective. TESOL Quarterly, 15(2), 117-124. Google Scholar

Xia, Dengshan, Yin, Caiyan, \& Lan, Chun. (2021). Chinese compliment responses in triadic contexts. Journal of Pragmatics, 174, 117-124. Google Scholar 


\section{Copyright holder:}

Muhammad Rizal Alfarisi (2021)

First publication right:

Syntax Literate: Jurnal Ilmiah Indonesia

This article is licensed under:

(c) (i) (?) 